\title{
Serendipity in the Stacks: Libraries, Information Architecture, and the Problems of Accidental Discovery
}

\section{Patrick L. Carr}

\begin{abstract}
Serendipity in the library stacks is generally regarded as a positive occurrence. While acknowledging its benefits, this essay draws on research in library science, information systems, and other fields to argue that, in two important respects, this form of discovery can be usefully framed as a problem. To make this argument, the essay examines serendipity both as the outcome of a process situated within the information architecture of the stacks and as a user perception about that outcome.
\end{abstract}

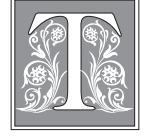

he potential of the stacks to facilitate serendipitous discovery provides a compelling evocation of the library's power as an instrument for research and learning. Many scholars can become inspired by visions of wandering through vast corridors of deserted stacks and then happening on a passage in some long-dormant volume that unexpectedly reveals a special insight. For some, the promise of such treasured discoveries is at the heart of deeply felt sentiments about the library's role in scholarship. English literature scholar Karen Lawrence, for example, writes that these forms of serendipitous discovery are "the lifeblood of intellectual activity," and legal historian Michael H. Hoeflich calls serendipity "a scholar's best friend" and asserts that "Each one of us, as teachers and as librarians or archivists, has an important role to play to keep serendipity alive."1

In this essay, I draw on research in library science, information systems, and other fields to explore the reasons for and potential implications of the high value that is generally attributed to serendipity in the stacks. Instead of considering how to keep this form of serendipity alive, I ask more fundamental questions concerning what serendipity in the stacks constitutes, how it relates to the functionalities that have been designed into the stacks, and how it might shape the meanings that users construct for libraries. Throughout my analysis, I argue that, in certain important respects, serendipity in the stacks can be usefully framed as a problem. By viewing this form of discovery through a critical lens, I do not intend to suggest that it has no value. Rather, my intention is to acknowledge and explore some of the largely overlooked problems that may accompany its benefits. Indeed, although serendipitous discoveries in the stacks may be "happy accidents," they are accidents all the same. Whereas most accounts of serendipity emphasize the happiness that accompanies these discoveries, my analysis foregrounds the processes and possible implications of their accidental nature.

Patrick L. Carr is Associate University Librarian for Collections \& Discovery at University of Connecticut; e-mail: patrick.l.carr@uconn.edu. (C2015 Patrick L. Carr 
To present my argument, I begin by briefly reviewing the concerns that some users have expressed about the imperilment of serendipity in the stacks. Next, I take a step back to briefly consider serendipity's meaning in the library context. In doing so, I draw on a study of serendipity in libraries performed by Abigail McBirnie to establish serendipity's dual existence as both an outcome of a process and as a perception regarding that outcome. ${ }^{2}$ Having described this dichotomy, I attempt to analyze serendipity in the stacks in both of its capacities. In my analysis of serendipity as an outcome of a process, I argue that there are useful insights to be gained by interpreting serendipity as a sign that certain intended library functionalities may not be effectively meeting users' needs. Regarding its perception, I consider how serendipity might shape the meanings that users construct for libraries and how those meanings might in turn influence the horizons for emergent library functionalities.

\section{The Imperilment of Serendipity in the Stacks}

Serendipity's presence in the stacks is, in the eyes of many, an imperiled phenomenon. As a report from the Education Advisory Board indicates, the transformative impacts of networked digital technologies are leading libraries to repurpose the space once devoted to open stacks and to instead enable users to search and discover collections through an array of powerful online tools. ${ }^{3}$ In the introduction to an OCLC Research report, Lorcan Dempsey notes that libraries are becoming increasingly aware of the opportunity costs of the area needed to facilitate the browsing of relatively little-used print collections. ${ }^{4}$ Space is at a premium, resources are scarce, and libraries are realizing new potentials for the shared management and stewardship of their "collective collections" of print materials. One consequence, Dempsey writes, is that libraries are reconfiguring space to support "social interaction around learning and research." ${ }^{5}$

As a result, some researchers believe that libraries are beginning to inhibit serendipity from occurring. Among the first to sound the alarm was journalism professor Ted Gup. ${ }^{6}$ In the 1997 Chronicle of Higher Education article "The End of Serendipity," Gup expresses an affinity for systems of organizing information that are "wondrously whimsical and exquisitely inefficient" and warns of the dangers posed to these systems by the World Wide Web. Sixteen years later, in another Chronicle of Higher Education article, composition instructor Julio Alves voices concerns that would seem to validate Gup's warnings. ${ }^{7}$ Alves writes that he is bothered that libraries are becoming "social spaces" rather than "homes for books" and mourns the decline and impending loss of "unintentional knowledge" to be gleaned by getting lost in the stacks.

Sociologist Andrew Abbott provides a theoretical basis for such concerns. ${ }^{8}$ Arguing that advanced research in the stacks is a nonstandardized, nonsequential, and artisanal endeavor, he claims that efforts to enhance library research through the introduction of new technologies are generally harmful due to their removal of randomness from processes for search and discovery. Indeed, Abbott holds that the placement of random elements (such as where an item is shelved and how a researcher flips through pages) within a highly organized architecture of information makes browsing in the stacks a singularly effective research method. On this and a number of other bases, he concludes that library users must defend their ability to engage in browsing and other traditional research methods "against the technologists, who have no idea what library research is or what it aims for, and against the administrators, who see in the false technological argument an intellectual justification for the huge savings they hope to realize by decommissioning libraries." 9

The library community is divided in its views regarding this perceived imperilment of serendipity. According to the interviews and analysis summarized in a report by the Education Advisory Board, some librarians are skeptical of the value of serendipity in 
the stacks. ${ }^{10}$ Among the reasons for skepticism are the limited holdings of the stacks, the possibility that items may be in use or misplaced, and the fact that related items are not always grouped together. In a much commented-on blog post, Brian Mathews elaborates on these concerns. ${ }^{11} \mathrm{He}$ argues that encouraging users to wander the stacks is "irresponsible" and that librarians should "teach students to be good searchers instead of lucky ones."

But many in the library community attribute greater value to serendipity and advocate that librarians ensure that serendipity has a continued presence in libraries. For example, articles appearing in the early 2000s by Elizabeth B. Cooksey and by Allen Foster and Nigel Ford both argue that librarians have a responsibility to create the conditions necessary to support serendipity. ${ }^{12}$ As Foster and Ford assert, "it is not only the prepared mind, but also the prepared retrieval system" that must be present for serendipity to occur. ${ }^{13}$ In her book Sacred Stacks, Nancy Kalikow Maxwell goes much further, advocating that libraries must enable users to "aimlessly wander the bookshelves." 14

More recently, in a plenary session at the 2013 Charleston Conference, Steven Bell claims that, due to a confluence of recent trends-including the relocation of collections to remote storage facilities, the implementation of automated storage and retrieval systems, and declining acquisitions of print materials-libraries are inadvertently impeding serendipity. ${ }^{15}$ In response, he advocates that librarians pursue new ways to cultivate serendipity. In another presentation at the same conference, Kate Joranson, Nina Clements, and Steve VanTuyl express similar sentiments. ${ }^{16}$ They argue that serendipitous discovery through browsing is a valued research strategy among many users, and they advocate that librarians collaborate with users, vendors, and each other to develop new tools to enable serendipity in digital environments.

To better understand the bases for and responses to the perceived imperilment of serendipity in the stacks, it is important to explore what serendipity is and how it relates to the functionalities that librarians have designed into libraries. An enriched understanding begins with a consideration of serendipity's meaning in the library context.

\section{Serendipity's Meaning in the Library Context}

"Serendipity" is a neologism coined by the English author, historian, and politician Horace Walpole, who introduced the word in a 1754 letter to his longtime friend and prolific correspondent Horace Mann. The letter describes how the title characters of the Persian fairy tale The Three Princes of Serendip are "always making discoveries, by accidents and sagacity, of things they were not in quest of," and, accordingly, Walpole proposes "serendipity" as a fitting appellation for such discoveries. For roughly a century following this initial instance of use, the word was forgotten. As Robert K. Merton and Elinor Barber show in their book The Travels and Adventures of Serendipity, the event that led to the word's gradual resurrection was the publication of Walpole's collected letters in the mid-1800s. ${ }^{17}$ Over the next century and a half, the word was gradually adopted by various communities, and today the word has reached a point of diffusion in which it is widely known in the popular vernacular.

Although essentially all uses of "serendipity" refer to some instance of accidental and pleasing discovery, varying communities have invested varying connotations into their use of the word. Within the academic community, serendipity is often associated with the sources and mechanics of intellectual insight. Many in this community have noted that a serendipitous discovery can only occur when a person is open to it. Indeed, Louis Pasteur's famous adage that "Chance favors the prepared mind" is widely embraced by academic researchers. From such a perspective, a necessary precondition to serendipity is, as Walpole stated, sagacity - that is, an engaged, flexible, 
and inquisitive intellect that, at the opportune moment, is capable of readily drawing connections between valued insights and what, to the unprepared mind, might seem like irrelevant information.

The application of a prepared mind to draw unexpected connections is also central to how serendipity is defined in the field of library science. For example, the International Encyclopedia of Information and Library Science defines serendipity as "the ability to perceive the potential or immediate utility of information encountered whilst not actively being sought at the time." ${ }^{18}$ Likewise, the entry for serendipity in the Dictionary for Library and Information Science explains that, in information retrieval, serendipity "usually depends on the ability of the browser to recognize the relevance or utility of data not actively sought at the time it is encountered." 19

While serendipity can happen anywhere, comments from library users suggest that serendipity's occurrence in the stacks can take on a special character that goes beyond the typical delight that accompanies any happy accident. This character seems to derive from the library's position as the traditional site of knowledge production in academia and in the feelings that this site evokes. Indeed, true to media theorist Marshall McLuhan's famous dictum that "The medium is the message," the qualities and resonances of the stacks seem to play a role in conditioning how users conceptualize the significance of the discoveries that occur there. ${ }^{20}$

Describing the demeanor that traditional research libraries impose, Maxwell writes that, upon entry, users "walk slowly, grow quiet, speak in whispers if they speak at all. Though indescribable, libraries evoke a feeling of goodness, power, and lasting importance that resembles that experienced in an old-fashioned church." 21 With its high vaulted ceilings and accompanying iconographies of rarified erudition, the traditional library suggests - to quote the esteemed journalist Carl Rowan-a "temple of learning." 22 According to Bohyun Kim, the "sense of awe and adventure" that the stacks convey comes as the result of the sensation that users have "of being 'physically" surrounded by knowledge." ${ }^{23}$ When serendipity occurs in this awe-inspiring setting, it can carry a powerful mystique. As Mathews remarks, "When an 'ah' happens in a romantic setting like a row of dusty stacks we feel that's a special moment." ${ }^{24}$

Beyond being a "special moment," serendipity in the stacks can include a spiritual dimension. Indeed, according to Jeffrey T. Schnapp and Matthew Battles, readers throughout recorded history have shown a tendency to regard serendipitous discoveries as spiritual revelations. ${ }^{25}$ This perception is evident, for example, in English literature scholar Nancy Lusignan Schultz and novelist Anne Lamott's characterizations of serendipitous discoveries in the stacks as "small miracles" and in Hoeflich's characterization of such discoveries as "blessings." 26 Of course, many users cite more rational bases for their understandings of serendipity. For example, in his recently published manual to library research, Digital Paper, Andrew Abbott argues that serendipity in the stacks is a "central constituent" of the research process. ${ }^{27}$ According to Abbott, browsers should self-consciously seek out random elements in the stacks' organization of information to stimulate the creativity that results in new knowledge. Likewise, through their interviews with faculty and librarians, Jennifer E. Nutefall and Phyllis Mentzell Ryder found that serendipitous discoveries are usually grounded in "a certain habit of mind or methodology." 28

However, to the extent that some users do in fact infuse spiritual elements into their descriptions of serendipity in the stacks, this phenomenon can perhaps be accounted for by what author Scott Berkun terms "the myth of epiphany." ${ }^{29}$ In the beginning of his book The Myths of Innovation, Berkun argues that humans demonstrate a desire to attribute discoveries to supernatural origins. According to the popular story, for example, Isaac Newton's discovery of gravity was primarily a result of an apple falling 
on his head. In reality, Berkun argues, such breakthroughs generally come as a result of difficult efforts of sustained and target inquiry. He writes that "it's not the apple or the magic moment that matters much, it's the work before and after." ${ }^{30}$ A similar statement seems applicable in response to a story that Dan Cohen relates in a blog post promoting the Digital Public Library of America's efforts to facilitate serendipity. ${ }^{31}$ Cohen writes of an incident in which, while browsing in the stacks, a professor discovered a new avenue in his scholarship by examining the contents of a book that fell on his head. Such a story appeals to the impulse described by Berkun to attribute inexplicable elements to discovery while deemphasizing the intellectual labors that likely played a much greater role in driving the breakthrough. ${ }^{32}$

Significantly, the above-discussed accounts of serendipity tend to present serendipity not just as a sensation but as a sensation tied to and resulting from specific ways of using the library. In doing so, the accounts reflect what McBirnie terms the "processperception duality" of serendipity. ${ }^{33}$ McBirnie identified this duality in research that she carried out to explore the hypothesis that library users might exhibit certain of the same improvisational characteristics as jazz musicians. After analyzing the results of interviews conducted with eight library researchers and two jazz musicians concerning their improvisational/research habits and their experiences with accidental discovery, McBirnie found that serendipity has a dual nature.

On the one hand, serendipity is tied to a process of information seeking. It is, in other words, a product of the tools that users employ in the course of search and discovery. On the other hand, serendipity is a perception; it is dependent on if and how users attribute value to the accidental discoveries that they encounter. Summarizing this "process-perception duality," McBirnie writes that the "Process-perception duality seems fundamental to serendipity; serendipity is neither only a process nor only a perception, but rather has a paradoxical nature dependent on conditions and context." ${ }^{34}$ The following two sections explore both sides of serendipity's dual nature: first as an outcome of a process within the stacks and then as a perception about this outcome.

\section{Serendipity as an Outcome of Information-Seeking Processes}

To understand the information-seeking processes that lead to serendipity in the stacks, it is first necessary to understand the fundamental qualities of the information environments in which serendipity can occur. For the present purposes, these information environments can be divided into three very broad categories. The first of the categories, which I call unstructured information environments, consists of environments in which order is absent. In these settings, chaos rules and information is dispersed randomly and without organizing principles. One example of such an environment is a dumpster filled with deselected library books. Here, the information seeker has little choice but to forage capriciously through the dumpster's contents without the ability to effectively map those contents.

In contrast, environments in the second category, which I call designer-centered information environments, contain information architectures. According to information design pioneer Peter Morville, an information architecture can, in its simplest terms, be defined as "the structural design of shared information environments." 35 In designer-centered information environments, the primary principles of structural design are the interests, agendas, and preferences of whoever successfully asserts control over the environments. In their most sinister manifestations, the information architectures are directed toward the surveillance and subjugation of bodies and minds. Instances of such architectures include the panoptic structures of open surveillance that philosopher Michel Foucault famously analyzes in Discipline and Punish, and, more recently, the "crytoptic" structures of clandestine electronic surveillance described by 
media theorist Siva Vaidhyanathan. ${ }^{36}$ These architectures can also reflect the efforts of designers to subtly influence behaviors; for example, retail outlets typically arrange their merchandise in the hopes of maximizing shoppers' purchases.

Like designer-centered information environments, the third category of environments, which I call user-centered information environments, also contains information architectures. Here, however, the principles of design are intended to address a broad community of users' needs rather than the designers' needs. It is, of course, in this category of information environments that libraries and their stacks belong. As Morville notes, "a major way that libraries and librarians add value to printed materials is by placing them within the framework of an information architecture that facilitates access to those materials." ${ }^{37}$ Indeed, to navigate through the stacks is to navigate through an environment that has been meticulously designed. Here we find ourselves in a vast and complex grid of ordered shelves. Here we find that on each shelf rest long rows of ordered volumes. And here we find each volume labeled with an alphanumeric code that attempts to map the volume's position both within the library's collection and within knowledge as a whole.

The design of this architecture facilitates two basic functions. One function (less relevant to the current analysis) is the storage and preservation of the materials in the stacks. The other function is to enable a process whereby users can easily navigate through print collections to either retrieve a known item or discover information on a known topic. The coordinates for the users' navigations are, of course, traditionally identified through the complementary information architecture embodied in the cata$\log$, which originally existed in paper formats (most famously, the card catalog) and which has subsequently transitioned to various digital formats (most famously, the online public access catalog, or OPAC). The catalog provides the user with a point of entry into the stacks: it tells the user where to find a known item in the stacks, and it also gives the user indicators regarding the appropriate area(s) in the stacks to apply targeted browsing to identify items concerning a known topic. Finally, the items themselves provide a final level of information architecture to complement the architecture of the stacks. Indeed, the basic design of the codex allows for easy browsing among pages of information, and table of contents and indices provide users with a means for searching through these pages. Thus, to use the catalog, the stacks, and the items that are shelved there is to interact with intricately structured information architectures that have been designed to solve specific problems for their user community.

If these information architectures have been designed effectively, then the outcomes of the information-seeking processes that occur in the stacks should reflect users' intentions. This is true even if the user's manner of interacting with these information architectures is not a linear one that begins with a clearly defined query and concludes with a clear resolution of the query. Marcia J. Bates, for example, describes a nonlinear "berrypicking" process for information seeking in which "the query is satisfied not by a single final retrieved set, but by a series of selections of individual references and bits of information at each stage of the ever modifying searching." ${ }^{38}$ During such "berrypicking," the user's query may be revised and refined, but it remains a deliberate process in which the outcome can be measured against the user's iterative intentions. Furthermore, nonlinear information-seeking processes can remain efficient processes insofar as they evolve in accordance with the evolving nature of the user's query. Indeed, while the winding paths of nonlinear research queries may seem inefficient, their circuitousness may in fact reflect the inherent complexities of formulating and refining an advanced research topic. In many cases, to browse in the stacks is to subject one's nascent research query to successive collusions with the already completed research queries embodied in the texts of the items being browsed. The outcome of 
these collusions can be to send the browser in an altered direction of enquiry. In short, a research query in the stacks can be a moving target. However, as long as the evolving outcomes of the browser's use of the stacks' information architecture are aligned with the browser's evolving intentions, the process can remain efficient.

Serendipitous discoveries, by contrast, are a misalignment of intention and outcome. Indeed, as I have noted in the previous section, the two primary encyclopedias in the library and information science field both characterize serendipity in the stacks as an unintentional outcome. ${ }^{39}$ Likewise, researchers in the fields of information science and human-computer interaction have also framed serendipity as a form of discovery that lacks intention. ${ }^{40}$ What I would suggest that this might imply is that serendipity in the stacks may be interpreted as an indicator that the stacks and their allied information architectures are, for the user's intended purposes, somehow faulty.

An example is helpful in illustrating this point. Consider an information-seeking process in which a user intends to locate a particular book in the stacks. The user has identified the book's call number; but, for whatever reason (maybe the book is incorrectly shelved or the cryptic coding system of the stacks causes the user to look in the wrong location), the user is unable to find the book. Nonetheless, in the course of the unsuccessful search process, the user does serendipitously discover another book in the stacks that contains valued but unrelated information. Even if this information were to prove to be more valuable to the user than the information in the book that was sought, the user's serendipitous discovery signifies a misalignment of user intention and process outcome. From a designer's point of view, the process that leads to such an instance of serendipity can be conceptualized as a sign of the limitations of the user-centered information environment in which the process is situated; serendipity exposes those limitations and occurs through them.

\section{Serendipity as a User Perception}

Although serendipity in the stacks can be interpreted as a process failure, it is not experienced as one. As research conducted by Nutefall and Mentzell has suggested, users view serendipity in the stacks "in a laudatory way." ${ }^{11}$ Sandra Erdelez reports that such laudatory feelings can result in users reshaping their information-seeking processes in a manner that increases the likelihood of future instances of serendipitous discovery. ${ }^{42}$ She writes that "the more that users find useful information by bumping into it while browsing, the more likely they are to pursue these same browsing patterns. This inclination in turn may result in more information-encountering experiences." ${ }^{43}$

One response to the inclinations of some users to experience serendipity in the stacks is to give these users what they want. In a prior article, I draw on S.R. Ranganathan's five laws of library science to argue that librarians should strive to make libraries userconstructed technologies and that they should resist urges to dictate the meanings of libraries to users. ${ }^{44}$ My arguments in that research could be interpreted to suggest that, with regard to serendipity, librarians should cede agency to their users as constructors of meaning by designing information architectures that facilitate the perception of serendipitous discovery in the stacks.

Such a course of action is particularly appealing in instances in which a user's serendipity exists as a perception only and not as the outcome of a process. Indeed, one important implication of the "process-perception duality" identified by McBirnie is that an instance of discovery may be experienced as serendipity even if, from a process-based standpoint, it is intentional. ${ }^{45}$ According to a literature review performed by Ronald E. Rice, Maureen McCreadie, and Shan-Ju L. Chan, library and information science researchers have generally characterized browsing in the stacks as falling into three basic categories: (1) "search browsing (directed browsing)," (2) 
"general purpose browsing (semi-directed or predictive browsing)," and (3) "serendipity browsing (undirected browsing)." ${ }^{46}$ Although only the last of these forms of browsing is truly unintentional, users engaging in the first two forms of browsing may nevertheless perceive their discoveries in the stacks as being serendipitous. In other words, some users may not be conscious of the methodological bases of their browsing in the stacks and, accordingly, may be inclined to view as accidental what is in fact intentional.

As discussed by John M. Budd, one field that is uniquely suited to examine the dynamics of intentionality and library discovery is phenomenology, a branch of philosophy that explores perception and consciousness. ${ }^{47}$ According to what Budd terms the "phenomenological attitude," researchers in library and information science can gain a deepened understanding of the activities of browsers who adopt "accepting stances" toward the unintended applicability of discoveries in the stacks. ${ }^{48}$ Erdelez, for example, has developed a body of research that explores the phenomenon of "opportunistic acquisition of information" as a framework for understanding how library browsers can find "interesting and useful information without purposeful application of information searching skills and strategies." 49

But even in instances where serendipity is only perceptual, there are factors that may reasonably dissuade librarians from taking steps to actively facilitate this perception. The most obvious of these factors is rooted in the economic reality that libraries operate in a context of scarce funding, personnel, and space. In this context, librarians cannot design their libraries to be all things for all users. Instead, they are often forced to consider tradeoffs and make either/or decisions about the allocation of scarce resources. To the extent that these either/or decisions concern the allocation of space, evidence suggests that the majority of users would not be well served by decisions that prioritize serendipity in the stacks. Survey data collected and analyzed by Ross Housewright, Roger C. Schonfeld, and Kate Wulfson shows that, from 2003 to 2012, faculty across the United States have increasingly come to rely on online search engines and databases for the discovery of scholarly resources. ${ }^{50}$ They also found that only a small and dwindling portion of faculty use the library building as the starting point for their research. Indeed, in 2013-2014 surveys of faculty at Indiana University and the University of North Carolina at Chapel Hill, less than 5 percent of respondents at both universities indicated that they use the library building as the starting point for their research. ${ }^{51}$

An additional reason why it may be problematic for librarians to facilitate the perception of serendipity in the stacks is rooted in the fact-compellingly articulated by technology theorist Nathan Crilly - that a technology can function to realize both tangible and intangible goals. ${ }^{52}$ This implies that the library can be understood not only as a practical tool for the search, discovery, and access of information but also as a symbolic tool reflective of the values and feelings of users. By situating the library as a tool that functions to facilitate serendipitous discovery in the stacks, librarians risk also situating the library as a mechanism that functions as a symbolic antithesis to the tools for discovery that are emerging in online environments. In this way, the library could signify a kind of bastion against change. Rather than being cast as a vital tool for meeting discovery needs in emergent online environments, the library could be marginalized in a way that suggests to users that they perceive it as a means of retreat from online environments.

Such a retreat has the potential to introduce feelings of nostalgia for a fading world in which information was scarcer and less structured. According to Morville, the emergent environment of networked computing is the harbinger for an age of "intertwingularity"; he writes that, in this age: 
We're creating new interfaces to export networked information while simultaneously importing vast amounts of data about the work into our networks. Familiar objects blur into this great intertwingling. Toilets sprout sensors. Objects consume their own metadata. Ambient devices, findable objects, tangible bits, wearables, and ingestibles are just some of the strange mutations residing in this borderland of atoms and bits. They are signposts on the road to ambient findability, a realm in which we can find anyone or anything from anywhere at any time..$^{53}$

One implication of this "intertwingularity" is that the realm of structured information is making ever more invasive incursions into the realm of unstructured information; all the world is being rendered as data in the network.

Among the drivers for these incursions are the personalization and integration of the information that users encounter in online platforms for discovery. By examining the behaviors and preferences of users, information designers continue to improve in their ability to refashion information architectures to reflect customized and targeted contents and services. As Morville writes, personalization occurs when "information and objects find us." ${ }^{54}$ For obvious reasons, personalization can facilitate accidental discovery. As online advertisers have long ago learned, the more that a platform can be personalized to reflect the kinds of information that users are drawn to, the easier it is for designers to engineer unanticipated connections into users' discovery experiences.

The concept of linked data is also facilitating unanticipated discoveries on online platforms. As defined by Tom Heath and Christian Bizer, linked data "refers to a set of best practices for publishing and interlinking structured data on the Web." ${ }^{55}$ In effect, linked data enables platforms to forge unanticipated but potentially valuable connections among disparate data sets. For example, the online tool "Serendip-o-matic" (serendipomatic.org/) aims to cultivate the experience of serendipity by comparing user-supplied texts against the linked data associated with materials that have been digitized by libraries, museums, and archives.

But personalization and linked data can also diminish the pleasing feelings that elevate accidental discoveries to sensations of serendipity. To the extent that users perceive that platforms are trying to think for them, their discoveries may be conceptualized not as triumphs of personal agency, intuition, and inspiration but as the covert mechanisms of a designer-centered information environment that aims to manipulate and control the avenues through which a person can construct knowledge. For example, a technical communications conference presentation by Carolyn Li-Madeo and Julia Marden on the potential of linked data to enhance the discovery of cultural heritage websites was met with skepticism by an attendee who, during the presentation's discussion period, shared concerns that linked data might impend the spontaneous workings of serendipity. ${ }^{56}$ Likewise, in his widely read book The Filter Bubble, Eli Pariser describes how personalization can detrimentally insulate a person from the discovery of diverse and unfamiliar perspectives. ${ }^{57}$

The pursuit of serendipity in the stacks can be interpreted as an act of symbolic resistance and as an attempt to recapture a sense of the freedom and mystery that is available in less networked information environments. While these efforts may seem sympathetic, I believe that librarians should be wary to facilitate them. Through facilitation, librarians could inadvertently inhibit the potentials of users to invest new meanings into library functionalities that align with their current information needs. According to the influential technology theorist Wiebe E. Bijker, a technology's meaning is socially constructed during an uptake process that gradually leads to a stabilization and closure of meaning. ${ }^{58}$ Libraries are, of course, a very old technology with a longstabilized meaning. However, in prior research, I have argued that the transformational 
changes in the current information landscape present a unique window during which libraries may have the opportunity to assume new meanings. ${ }^{59}$ In this historical moment, framing the library as a symbolic refuge from change can have a stultifying effect. It can prevent users from using the library in ways that are organically related to their immediate and evolving information needs, and, as a result, it can close off new horizons of meaning.

\section{Conclusion}

According to Morville, a library constitutes not just an information architecture but an "inspiration architecture." ${ }^{60}$ This architecture, he writes, "reminds us that the path to discovery isn't always, or even usually, a straight line," and it enables us "to explore strange connections between intellect and emotion, wisdom and knowledge, mind and body." Morville's comments are of note because they suggest a useful counterpoint to my forgoing analysis of serendipity in the stacks. My analysis has taken a largely reductive approach focused on efficiency, intention, and outcome. Although - if it was successful - this analysis has provided some insights into serendipity's relationship with certain fundamental elements of library functionality and human experience, it also has the possible drawback of oversimplification. Morville, in contrast, foregrounds both the inspirational power and complexities of discovery in libraries, suggesting that, in many cases, the processes and perceptions entailed in serendipity cannot be easily defined or clearly delineated from other processes and perceptions.

While acknowledging the validity of Morville's points, I nevertheless believe that, along with its positive aspects, serendipity in the stacks can be usefully framed as a problem. From a process-based standpoint, serendipity is problematic because it is an indicator of a potential misalignment between user intention and process outcome. And, from a perception-based standpoint, serendipity is problematic because it can encourage user-constructed meanings for libraries that are rooted in opposition to change rather than in users' immediate and evolving information needs.

I believe that, for librarians wishing to enable libraries to play a vital role in the emergent information environment, there is significant value in an awareness of the problems that serendipity in the stacks can pose. Indeed, while it seems unlikely that most users will begin adopting a critical stance toward serendipity in the stacks, librarians today will benefit from an understanding of the problematic processes and perceptions that may underlie this form of discovery. Through this understanding, librarians can strive to design functionalities into libraries that make informed and strategically deft uses and/or disuses of serendipity. More specifically, they can become better equipped to develop solutions that balance a complex set of discovery-related priorities and concerns. They can strive to realize the "inspiration architectures" of which Morville writes while also developing information architectures that align outcomes with user intentions and that invite users to see beyond traditional notions of libraries. ${ }^{61}$

\section{Notes}

1. Karen Lawrence, "Reinvention of the Library: Looking Forward While Looking Back," Continuum 6, no. 3 (1996/1997), available online at https://www.alumni.utah.edu/continuum/ winter96/library.html [accessed 6 December 2014]; Michael H. Hoeflich, "Serendipity in the Stacks, Fortuity in the Archives," Law Library Journal 99, no. 4 (2007): 827.

2. Abigail McBirnie, "Seeking Serendipity: The Paradox of Control," Aslib Proceedings: New Information Perspectives 60, no. 6 (2008): 600-18, doi:10.1108/00012530810924294\#sthash.gOoOfZyr. dpuf.

3. Education Advisory Board, Redefining the Academic Library: Managing the Migration to Digital Information Services (Washington, D.C.: The Advisory Board Company, 2011): 55, available online at http://www.eab.com/research-and-insights/academic-affairs-forum/studies/2011/redefining- 
the-academic-library [accessed 29 March 2014].

4. Lorcan Dempsey, "The Emergence of the Collective Collection: Analyzing Aggregate Print Library Holdings," in Understanding the Collective Collection: Towards a System-wide Perspective on Library Print Collections, Lorcan Dempsey, Brian Lavoie, Constance Malpas, Lynn Silipigni Connaway, Roger C. Schonfeld, J.D. Shipengrover, and Günter Waibel (Dublin, Ohio: OCLC Research, 2013): 1-10, available online at http://oclc.org/content/dam/research/publications/ library/2013/2013-09intro.pdf [accessed 6 December 2014].

5. Ibid., 4 .

6. Ted Gup, "The End of Serendipity," Chronicle of Higher Education 44, no. 13 (1997): A52.

7. Julio Alves, "Unintentional Knowledge: What We Find When We're Not Looking," Chronicle of Higher Education 59, no. 41 (2013), available online at http://chronicle.com/article/UnintentionalKnowledge/139891/ [accessed 6 December 2014].

8. Andrew Abbott, "The Traditional Future: A Computational Theory of Library Research," College \& Research Libraries 69, no. 6 (2008): 524-45.

9. Ibid., 542.

10. Education Advisory Board, Redefining the Academic Library, 55.

11. Brian Mathews, "Haystacks vs. Algorithms: Is Scanning the Stacks for (Pretty) Books Really the Best Research Strategy?" The Ubiquitous Librarian (blog) (2013), available online at http:// chronicle.com/blognetwork/theubiquitouslibrarian/2013/06/25/haystacks-vs-algorithms-is-scanning-the-stacks-for-pretty-books-really-the-best-research-strategy/ [accessed 6 December 2014]

12. Elizabeth B. Cooksey, "Too Important to Be Left to Chance-Serendipity and the Digital Library," Science \& Technology Libraries 25, no. 1/2 (2004): 23-32, doi:10.1300/J122v25n01_03; Allen Foster and Nigel Ford, "Serendipity and Information Seeking: An Empirical Study." Journal of Documentation 59, no. 3 (2003): 321-40, doi:10.1108/00220410310472518.

13. Foster and Ford, "Serendipity and Information Seeking," 325.

14. Nancy Kalikow Maxwell, Sacred Stacks: The Higher Purpose of Libraries and Librarianship (Chicago: American Library Association, 2006), 131.

15. Steven Bell, "Collections Are for Collisions: Let's Design It into the Experience" (presentation, Charleston Conference, Charleston, S.C., Nov. 6-9, 2013).

16. Kate Joranson, Steve Van Tuyl, and Nina Clements, "E-Browsing: Serendipity and Questions of Access and Discovery" (presentation, Charleston Conference, Charleston, S.C., Nov. 6-9, 2013).

17. Robert K. Merton and Elinor Barber, The Travels and Adventures of Serendipity (Princeton, N.J.: Princeton University Press, 2004).

18. The International Encyclopedia of Information and Library Science, 2nd ed., eds. John Feather and Paul Sturges (London: Routledge, 2003), 574.

19. Joan M. Reitz, Dictionary for Library and Information Science (Westport, Conn.: Libraries Unlimited, 2004), 648.

20. Marshall McLuhan, Understanding Media: The Extensions of Man (New York: McGraw Hill, 1964), 7.

21. Maxwell, Scared Stacks, 78

22. Quoted in The Librarian's Book of Quotes, comp. Tatyana Eckstrand (Chicago: American Library Association, 2009), 12.

23. Bohyun Kim, "Enabling the Research 'Flow' and Serendipity in Today's Digital Library Environment," ACRLog (blog) (2012), available online at http://acrlog.org/2012/10/29/enabling-theresearch-flow-and-serendipity-in-todays-digital-library-environment/ [accessed 6 December 2014].

24. Mathews, "Haystacks vs. Algorithms."

25. Jeffrey T. Schnapp and Matthew Battles, The Library beyond the Book (Cambridge, Mass.: Harvard University Press, 2014), 90-91.

26. Nancy Lusignan Schultz, "Serendipity in the Archive," Chronicle of Higher Education 57, no. 37 (2011), available online at http://chronicle.com/article/Serendipity-in-the-Archive/127460/ ?key=T2J2clE+ZndDMCtlNTtFY2oGaXU/NUJzYnBLYisoblBXFg== [accessed 6 December 2014]; Anne Lamott, Plan B: Further Thoughts on Faith (New York: Riverhead Books, 2005), 143; Hoeflich, "Serendipity in the Stacks, Fortuity in the Archives," 814.

27. Andrew Abbott, Digital Paper: A Manual for Research and Writing with Library and Internet Materials (Chicago: University of Chicago Press, 2014), 119.

28. Jennifer E. Nutefall and Phyllis Mentzell Ryder, "The Serendipitous Research Process," Journal of Academic Librarianship 36, no. 3 (2010): 231, doi:10.1016/j.acalib.2010.03.005.

29. Scott Berkun, The Myths of Innovation (Sebastopol, Calif.: O'Reilly, 2010): 1.

30. Ibid., 8.

31. Dan Cohen, "Planning for Serendipity," Digital Public Library of America (blog) (2014), available online at http://dp.la/info/2014/02/07/planning-for-serendipity/ [accessed 6 December 2014].

32. Berkun, The Myths of Innovation.

33. McBirnie, "Seeking Serendipity," 607. 
34. Ibid., 608 .

35. Peter Morville,.Intertwingled (Ann Arbor, Mich.: Semantic Studios, 2014), 7.

36. Michel Foucault, Discipline and Punish: The Birth of the Prison (New York: Pantheon Books, 1977); Siva Vaidhyanathan, "Googlization and the Challenge of Big Data" (presentation, NASIG Annual Conference, Buffalo, N.Y., June 6-9, 2013).

37. Peter Morville, Information Architecture for the World Wide Web (Sebastopol, Calif.: O'Reilly, 2007), 7.

38. Marcia J. Bates, "The Design of Browsing and Berrypicking Techniques for the Online Search Interface," Online Review 13, no. 5 (1989): 410.

39. Feather and Sturges, International Encyclopedia of Information and Library Science, 574; Reitz, Dictionary for Library and Information Science, 648.

40. Sandra Erdelez, "Information Encountering: A Conceptual Framework for Accidental Information Discovery," in Information Seeking in Context, eds. Pertti Vakkari, Reijo Savolainen, and Brenda Dervin (London: Taylor Graham, 1997), 412-21; Oscar De Bruijn and Robert Spence, "A New Framework for Theory-based Interaction Design Applied to Serendipitous Information Retrieval," ACM Transactions on Computer-Human Interaction 15, no. 1 (2008): 5.

41. Nutefall and Ryder, "The Serendipitous Research Process," 231.

42. Sandra Erdelez, "Information Encountering: It's More Than Just Bumping into Information," Bulletin of the American Society for Information Science 25, no. 3 (1999): 25-29.

43. Ibid., 28.

44. Patrick L. Carr, "Reimagining the Library as a Technology: An Analysis of Ranganathan's Five Laws of Library Science within the Social Construction of Technology Framework," Library Quarterly 84, no. 2 (2014): 152-64.

45. McBirnie, "Seeking Serendipity," 607.

46. Ronald E. Rice, Maureen McCreadie, and Shan-Ju L. Chan, Accessing and Browsing Information and Communication (Cambridge, Mass.: MIT Press, 2001), 179.

47. John M. Budd, "Phenomenology and Information Studies," Journal of Documentation 61, no. 1 (2005): 44-59, doi.10.1108/00220410510578005.

48. Ibid., 55 .

49. Sandra Erdelez, "Investigation of Information Encountering in the Controlled Research Environment," Information Processing and Management 40, no. 6 (2004): 1013, doi:10.1016/j. ipm.2004.02.002.

50. Ross Housewright, Roger C. Schonfeld, and Kate Wulfson, Ithaka S+R Faculty Survey 2012 (New York: Ithaka S+R, 2013): 21, available online at www.sr.ithaka.org/sites/default/files/reports/ Ithaka_SR_US_Faculty_Survey_2012_FINAL.pdf [accessed 6 December 2014].

51. Roger C. Schonfeld, Does Discovery Still Happen in the Library? Roles and Strategies for a Shifting Reality (New York: Ithaka S+R, 2014): 9, available online at http://www.sr.ithaka.org/sites/default/ files/files/SR_Briefing_Discovery_20140924_0.pdf [accessed 6 December 2014].

52. Nathan Crilly, "The Roles That Artefacts Play: Technical, Social, and Aesthetic Functions," Design Studies 31, no. 4 (2010): 311-44, doi:10.1016/j.destud.2010.04.002.

53. Peter Morville, Ambient Findability (Sebastopol, Calif.: O’Reilly, 2005): 64-65.

54. Ibid., 115.

55. Tom Heath and Christian Bizer, Linked Data: Evolving the Web into a Global Data Space (1st Edition). Synthesis Lectures on the Semantic Web: Theory and Technology, (Morgan \& Claypool, 2011), 7.

56. Carolyn Li-Madeo and Julia Marden, "Linked Open Data for Cultural Heritage: Evolution of an Information Technology" (presentation, Association for Computing Machinery Special Interest Group on the Design of Communication Conference, Greenville, N.C., Sept. 30-Oct. 1, 2013).

57. Eli Pariser, The Filter Bubble: What the Internet Is Hiding from You (New York: Penguin Press, 2011).

58. Wiebe E. Bijker, “How Is Technology Made?-That Is the Question!" Cambridge Journal of Economics 34, no. 1 (2010): 69, doi:10.1093/cje/bep068.

59. Carr, "Reimagining the Library as a Technology."

60. Peter Morville, "Inspiration Architecture: The Future of Libraries," in Library 2020: Today's Leading Visionaries Describe Tomorrow's Library, ed. Joseph Janes (Lanham, Md.: Scarecrow Press, 2013), 143.

61. Ibid. 